\title{
Tiny House Village sebagai Solusi Minimnya Lahan di Surabaya dan sebagai Solusi Pola Hidup Sederhana
}

\author{
Inggrit Eka Pratiwi ${ }^{1}$, Esty Poedjioetami ${ }^{2}$ \\ ${ }^{1}$ Jurusan Arsitektur, Fakultas Teknik Sipil dan Perencanaan, Institut Teknologi Adhi Tama Surabaya \\ ${ }^{2}$ Jurusan Arsitektur, Fakultas Teknik Sipil dan Perencanaan, Institut Teknologi Adhi Tama Surabaya \\ Email: ${ }^{\text {inggitt@gmail.com }}$
}

\begin{abstract}
Surabaya is the second largest metropolis city in Indonesia. This makes Surabaya has a lot of jobs, causing many people from out of town to move and settle in Surabaya. The number of residents who move and settle in Surabaya is not proportional to the amount of land available as a place to live. The Micro House is designed using a modern tropical concept to suit the climatic conditions in Surabaya. using descriptive research methods by conducting observations and comparative studies both in the field and literature with a comparative study in the field of akanoma studio, bandung and royal caravan trawas. Besides a comparative study of literature using the slow town tiny house, South Korea and the UN \& Yale University tiny house in New York. From the observations, data on land arrangements, shapes and spaces can be used as a reference for designing Tiny House Village. Site analysis can be determined macro concepts tropical architecture and the micro concept of land structure; "dynamic", shape: "natural" and space: "effective". This house is thought to be a solution to the lack of land and the increasing need for housing and can be used for people who want a simple lifestyle, with a smaller size but have complete facilities like a house in general.
\end{abstract}

Keywords: Concept, Lamd, Tiny And Small House, Surabaya, Tropical

\begin{abstract}
Abstrak. Surabaya merupakan kota metropolis terbesar kedua di Indonesia.hal ini menjadikan Surabaya memiliki banyak lapangan pekerjaan sehingga menyebabkan banyak orang dari luar kota pindah dan menetap di Surabaya banyaknya penduduk yang pindah dan menetap di Surabaya tidak sebanding dengan jumlah lahan yang tersedia sebagai tempat tinggal. Rumah Mikro ini dirancang menggunakan konsep modern tropis agar sesuai dengan kondisi iklim yang ada di Surabaya. menggunakan metode penelitian dekriptif dengan melakukan observasi dan studi banding baik secara lapngan maupun literaturr dengan studi banding lapngan di studio akanoma bandung dan royal caravan trawas. Juga studi banding literature menggunakan slow town tiny house, korea selatan dan un \& yale university tiny house di new york. Dari hasil observasi didapatkan data mengenai tatanan lahan, bentuk dan ruang yang dapat diguanakan sebagai acuan untuk mendesain Tiny House Village, dengan analisis program ruang dan analisis tapak dapat ditentukan konsep makro yaitu arsitektur tropis dan konsep mikro tatanan lahan: "dinamis", bentuk: "natural" dan ruang: "efektif" yang digunakan dalam merancang. Tiny house ini dirasa mampu menjadi solusi kurangnya lahan dan semakin menigkatnya kebutuhan akan rumah tinggal dan dapat digunakan untuk orang-orang yang menginginkan pola hidup sederhana.dengan ukuran yang ebih kecil namun memiliki fasilitas yang lengkap layaknya rumah pada umumnya.
\end{abstract}

Kata Kunci: Konsep, Lahan, Rumah Mikro, Surabaya, Tropis.

\section{Pendahuluan}

Kota Surabaya adalah kota besar ibukota Jawa Timur yang merupakan kota metropolitan dan kota terbesar kedua di indonesia setelah Jakarta. Surabaya sebagai kota dengan pusat bisnis dan industri menyebabkan banyak penduduk dari kota-kota lain yang berpindah ke Surabaya untuk mencari pekerjaan dan hidup menetap di Surabaya. Hal ini menyebabkan pesatnaya populasi penduduk di Surabaya. Kepadatan penduduk mengakibatkan meningkatnya kebutuhan lahan untuk hunian sehingga menyebabkan meroketnya harga kavling tanah di Surabaya sehingga mempengaruhi kelayakan tempat tinggal hunian di Surabaya.

Permasalahan ini juga sering dihadapi oleh kota-kota besar di seluruh dunia.sehingga muncul solusi rumah mikro atau tiny house yang mampu mengatasi masalah kurangnya ketersediaan lahan dan keinginan untuk memiliki pola hidup yang sederhana.selain itu banyaknya kalamgan orang yang 
meramalkan bahwa di masa depan generasi milenial akan susah untuk memiliki tempat tinggal mereka sendiri dikarenakan kebutuhan ekonomi yang semakin meningkat yang menyebabkan semua harga kebutuhan menjadi mahal. Tiny house dirasa juga dapat menjadi solusi low cost building yang dapat memenuhi kebutuhan akan rumah tinggal.

Tiny house village ini dirancang untuk mengatasi kebutuhan rumah tinggal bagi kalangan menegah dan kebawah sehingga dapat memiliki huniannya sendiri, lengkap dengan fasilitas pendukung yang mampu menjadi sumber ekonomi masyarakat yang tinggal di dalam perumahan rumah mikro ini. Dengan begitu mampu menghasilkan sinergi antara lingkungan sekitar, bangunan dan penghuninya. Hal ini tidak lepas dari penggunaan tema tropis modern yang dapat beradaptasi dengan iklim atau cuaca yang ada di Surabaya sehingga mamu mengurangi penggunaan listrik untuk pencahaayan dan penghawaan sehingga lebih hemat energi.

\subsection{Tinjauan Pustaka}

Menurut Congress Internationaux D'architecture Modern (CIDM), 1928 Arsitektur Modern dapat diartikan sebagai pernyataan jiwa dari satu masa, yang dapat menyesuaikan diri dengan perubahan sosial ekonomi yang ditimbukkan pada zamannya, yaitu dengan mencari keharmonisan dari elemen modern serta mengembalikan arsitektur pada bidang yang sebenarnya ekonomis, sosiologis, dan kemasyarakatan).

Menurut Kania Dekoruma, 17 juli 2018. Arsitektur tropis adalah konsep arsitektur yang mampu beradaptasi dengan kondisi iklim tropis. Iklim tropis sendiri memiliki karakter tersendiri seperti sinar matahari yang panas sepanjang tahun, kelembaban udara yang cukup tinggi, curah hujan tinggi, angin, serta kondisi udara yang berbeda. Kondisi inilah yang perlu diperhatikan agar arsitektur tropis mampu menghadirkan fungsi dan kenyamanan terbaik untuk penghuni rumah.

Menurut Dr. Sri Handayani M.Pd pada bukunya yang berjudul arsitektur dan lingkungan menyatakan bahwa green architecture adalah konsep arsitektur yang berusaha meminimalisisr pengaruh negatif terhadap lingkungan sekitar maupun manusia dan menghasilkan tempat hidup yang lebih baik dan lebih sehat .yang dilakukan dengan cara memanfaatkan sumber energy dan sumber daya alam yang ada secara efisien dan optimal. Konsep arsitektur hijau sendiri bertanggung jawab terhadap lingkungan, memiliki tingkat keselarasan yang baik antara struktur dan lingkungannya. Hal itu tentu saja disertai penggunaan sitem utilitas yang sebaik mungkin.

\subsection{Metode Penelitian}

Jenis metode penelitian yang digunakan dalam menyusun perencanaan dan perancangan Tiny House Village di Surabaya ini menggunakan penelitian deskriptif kualitatif yaitu Nazir (1988:63) Metode Deskriptif merupakan suatu metode dalam meneliti status sekelompok manusia, suatu objek, suatu set kondisi, suatu sistem pemikiran ataupun suatu kelas peristiwa pada masa sekarang. Tujuan dari penelitian deskriptif ini adalah untuk membuat deskripsi, gambaran, atau lukisan secara sistematis, faktual dan akurat mengenai fakta-fakta, sifat-sifat serta hubungan antarfenomena yang diselidiki.

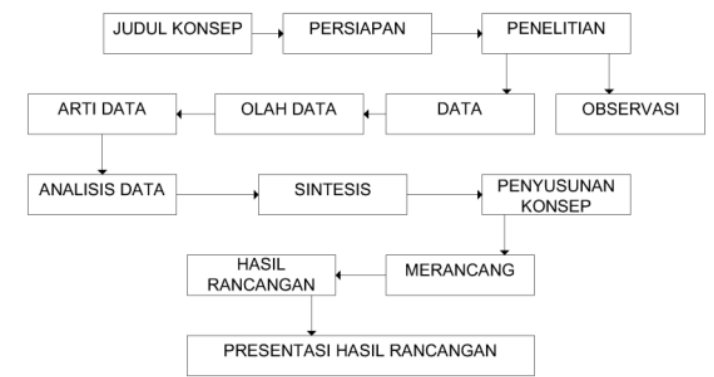

Gambar 1. Diagram metode penelitian

\section{Pembahasan}

Hasil observasi studi banding secara lapangan dan literatur menhasilkan data yang dapat digunakan untuk merancang dan atau membuat program ruang serta desain pada tiny house village ini. 
Studi banding lapangan dilakukan di Studio Akanoma, Bandung dan Royal Caravan Hotel di Trawas. studi banding literatur menggunakan Slow Town Tiny House oleh The Plus Partners + DNC Architect, Korea Selatan dan UN \&Yale University Tiny House, New York.

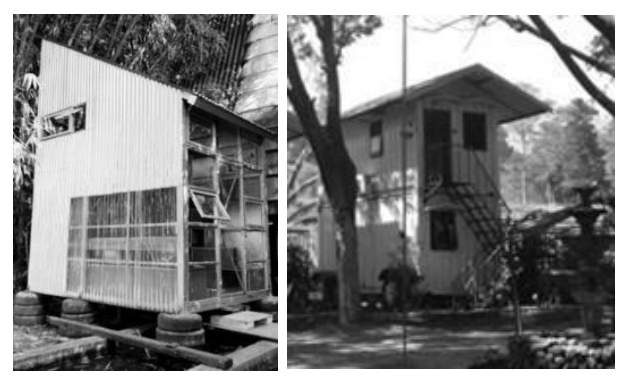

Gambar 2. Studi banding lapangan: rumah mikro (kiri) Aknoma, (kanan) Royal Caravan

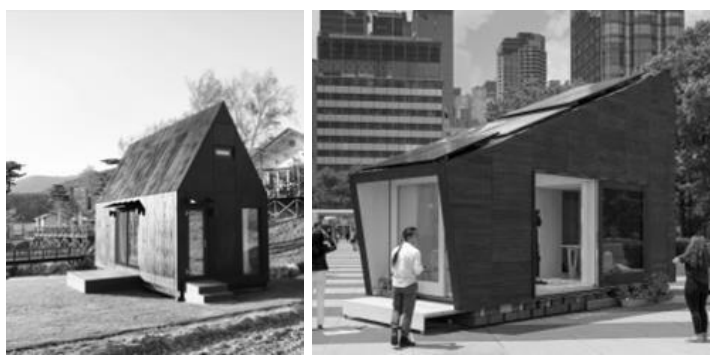

Gambar 3. Studi banding literatar: rumah mikro (kiri) slow town tiny house, (kanan) UN \& YALE tiny house

sumber: (kiri) moobum jang, https://www.archdaily.com/799674/slow-town-tiny-house-the-plus-partners-plusdnc-architects (kanan) (David Sundberg/Esto,https://www.archdaily.com/898561/un-and-yale-university-unveil-tiny-house-as-the-futureof-eco-living?ad_source $=$ search\&ad_medium=search_result_all

Setelah melakukan studi banding lapangan dan litertaur dapat dibuat kesimpulan bahwa adanya kelebihan dan kekurangan dalam desain tersebut sehingga dapat menjadi contoh dalam merancang dengan tentunya dilakukan perbaikan agar manghasilkan rancangan yang lebih baik dan sesuai dengan kebutuhan. Metode penyusunan program ruang menggunakan metode form follows function di mana bentuk mengikuti fungsi bangunan. Sehingga ruang-ruang yang dihasilkan sesuai dengan fungsinya yang mana bentuk ruang yang sesuai dengan fungsi akan mempermudah aktivitas yangterjadi di dalam ruangan tersebut. Pada tiny house village ini memiliki banyak massa bangunanyang mana terdiri dari unit tiny house, unit penginapan, unit home industry, unit kios denganpenghubung antar massa berupa taman.
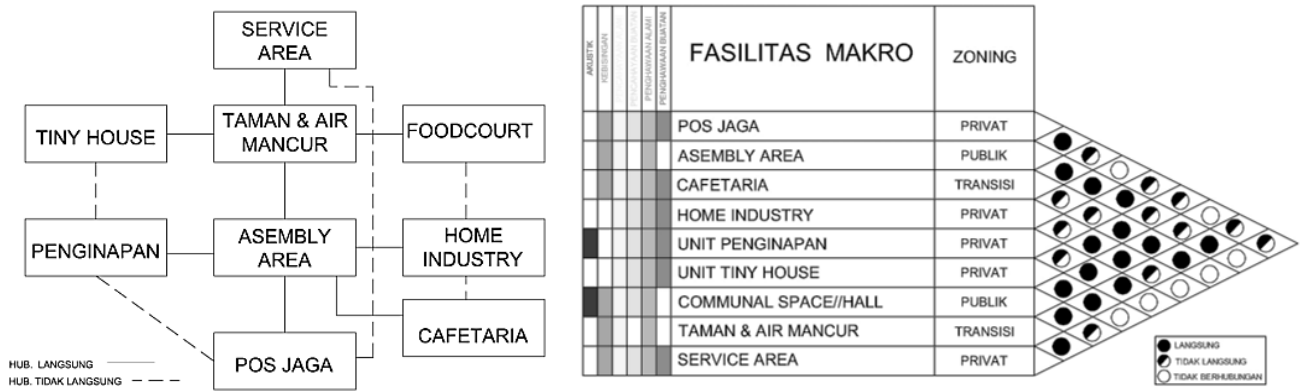

Gambar 4. (kiri) diagram organisasi massa makro, (kanan) diagram hubungan ruang makro

Site menggunakan tapak dengan ukuran kurang lebih 0,8 hektar yang berada di lokasi Medokan Asri, lokasi ini dipilih karena memiliki harga tanah yang relatif murah dibandingkan dengan area lain di Surabaya dengan harga tanah Rp.4.000.000,- sampai dengan Rp.5.000.000,- dibandingkan dengan kawasan elite lain di Surabaya. 


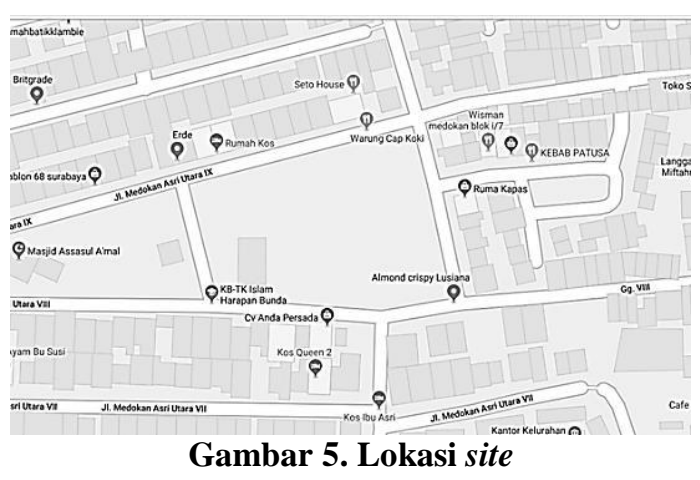

Zonifikasi pada site dibuat menjadi 3 aspek pokok yaitu zonifikasi publik, zonifikasi transisi dan zonifikasi privat. Zona-zona tersebut selanjutnya direncanakan bangunan yang menyesuaikan fungsi dan jenis zoning yang dibutuhkan. Hal itu dilakukan dengan tujuan agar tidak bercampur antara fasilitas yang bersifat untuk umum atau publik, dan atau dengan fasilitas yang bersifat privat. Perletakan zona publik direncanakan di sisi terluar site, zona transisi di antara zona public dan zona privat, sedangkan zona privat terletak di tengah site.

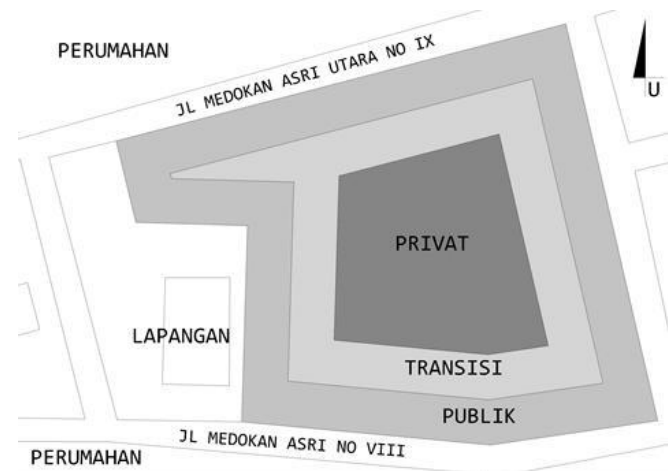

Gambar 6. Zonifikasi

Menggunakan konsep makro arsitektur tropis yang mampu beradaptasi dengan iklim tropis yang mampu menghadirkan kenyamanan termal yang baik sehingga memiliki fungsi terbaik bagi penghuni rumah. Dengan konsep mikro tatanan lahan: "dinamis", konsep mikro bentuk: "natural", dan konsep mikro ruang: "efektif".

Konsep mikro tatanan lahan: "dinamis" dengan menata masa bangunan dengan tatanan yang dinamis, diekspresikan melalui tatanan maju-mundur dengan beberap bagian dibuat saling berhubungan.

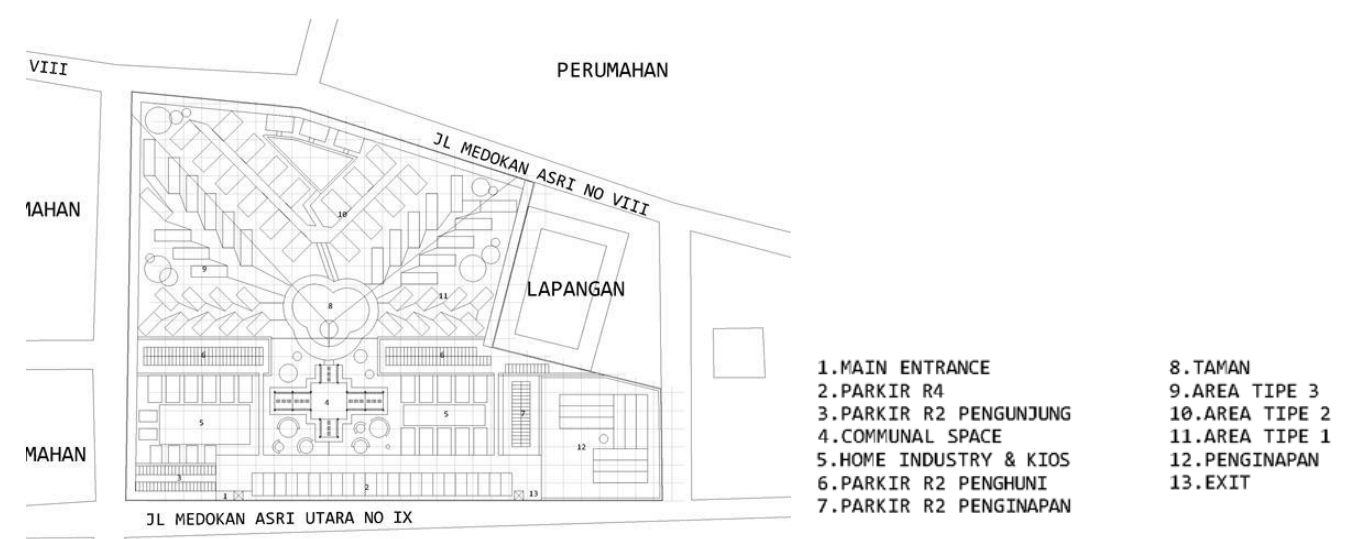

Gambar 7. Rencana tatanan lahan Tiny House Village 
Konsep mikro bentuk: "natural" dengan menggunakan bentuk yang mampu bersinergi dengan lingkungan sekitar dan menggunakn material yang dapat didapat di daerah lokal sehingga memiliki harga yang lebih murah dan mudah dijangkau.

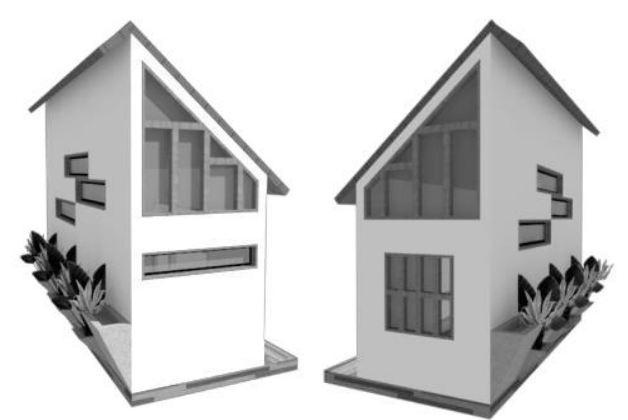

Gambar 8. Rencana desain bentukan Tiny House

Konsep mirko ruang: "efektif" agar seluruh bagian dari bangunan dapat digunakan se-efektif mungkin atau semaksimal mungkin dengan luasan bangunan yang mungil atau lebih kecil dari rumah tinggal standar.

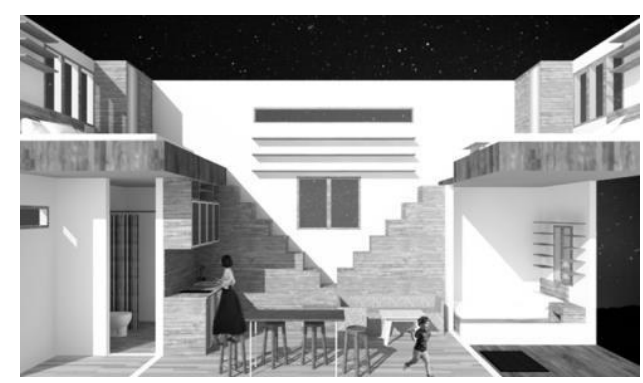

Gambar 9. Interior Tiny House

\section{Kesimpulan}

Surabaya merupakan kota terbesar kedua di Indonesia yang menyebabkan kota ini padat penduduk, padatnya penduduk menyebabkan kurangnya hunian dikarenakan berkuranganya lahan. Maka dari itu tiny house village ini dirasa mampu menjadi solusi permasalahan ini.

Desain yang dihasilkan didapatkan dari studi banding yang dilakukan, baik studi literatur dan studi lapangan sehingga menghasilkan data dan gambaran untuk membuat desain tiny house yang lebih baik. Pemilihan site diletakkan di Jalan Medokan Ayu dengan alasan harga tanah yang murah sehingga dapat dijangkau oleh semua kalangan masyarakat menengah dengan gaji stabil dan keluarga muda atau bahkan remaja. Menggunakan konsep modern tropis supaya sesuai dengan iklim yang ada di Surabaya sehingga meminimalisisr penggunaan pencahayaaan dan penghawaan buatan sehingga lebih hemat energi.

\section{Referensi}

Congress Internationaux D'Architecture Modern (CIDM). 1928.

Handayani, Sri. 2009. Arsitektur dan Lingkungan. Bandung: Penerbit Universitas Pendidikan Indonesia. Nazir. 2011. Contoh Metode Penelitian. Bogor: Ghalia Indonesia Website

“Apa Itu Arsitektur Tropis". Diakses dari: https://www.dekoruma.com/artikel/71645/apa-itu-arsitektur$\underline{\text { tropis }}$ 
